\title{
A Study of the Impact of Cloud Computing Alignment on the Enterprise Technological Capability Based on Environmental Turbulence
}

\author{
SHAO MingXing ${ }^{1, \mathrm{a}}$, YANG XiaoHe $^{1, \mathrm{~b}}$ \\ ${ }^{1}$ International Business School, Beijing Foreign Studies University, Beijing, China
}

\begin{abstract}
One of the most current concerns in the field of information system is whether cloud computing technology can deliver the desired improvement of capability and value to enterprises. This paper studied the enterprise technology development capability of the enterprises in Beijing Zhongguancun Technology Park, the first national high-tech industrial development zone in China, from the perspective of the breadth and depth of the alignment of cloud computing and enterprise. It proposed a theoretical model to study how the breadth and depth of alignment affects the enterprise technology development capability in a turbulent environment and considers the intermediary role of the enterprise technology absorption capability and the moderation role of environmental turbulence in it. The model was tested empirically by questionnaires and structural equation model (SEM). Empirical results showed that both the deep and wide alignment of cloud computing can enhance the enterprise technology development capability by improving the enterprise technology absorption capability.
\end{abstract}

\section{Introduction}

An important and long-standing concern in the field of information systems is whether information technology can bring about the expected technological advances and capability improvements for enterprises when it is adopted and implemented. Thus, while cloud computing has the excellent characteristics of flexibility and pay-per-use feature[1], many enterprise users remain wait-and-see or even skeptical about the role and value of cloud computing. In the last two years, there has been a great deal of academic interest in how cloud computing can enhance the capability of enterprises, particularly the technological capability that enable them to undertake technological activities to develop new products and processes.

As China's first national high-tech industrial development zone, Zhongguancun Technology Park is known as "China's Silicon Valley", home to over 10,000 high-tech enterprises. After preliminary research and interviews, we found that most of the enterprises in Zhongguancun Technology Park are using cloud computing services, and many enterprises have moved most of their business to the cloud, making Zhongguancun Technology Park an important base for cloud computing practice and implementation. Therefore, for enterprises in Zhongguancun Technology Park that have achieved the alignment of cloud computing, can alignment enhance their technological capability? This is a key issue that will ultimately drive the adoption and application of cloud computing.
To address this issue, this paper proposed a theoretical model to study how alignment breadth and depth affects the enterprise technology development capability by influencing its technology absorption capability and considered the moderation role of environmental turbulence in it. Finally, we validated the proposed research model and research hypotheses through empirical studies, which provided a basis for the theoretical and industry understanding of how cloud computing alignment can enhance enterprise technological capability.

\section{Research model and research hypotheses}

\subsection{Alignment of Cloud Computing and Enterprise}

Cloud computing alignment refers to the extent to which cloud computing and business activities at all levels of an organization are coordinated and integrated with each other[2]. The purpose of the alignment of business and cloud computing is to improve business performance, or to bring value to the business on a broader scale. Cloud computing alignment can be further divided into two aspects, breadth and depth[2].

The breadth of the alignment indicates the scope in which cloud computing has been aligned with corporate business, from its use in individual departments to its eventual alignment with business processes in all departments. In terms of depth, the alignment of business

ae-mail: shaomingxing@bfsu.edu.cn be-mail: 646362225@qq.com 
and cloud computing will go through a development process from superficial to deep and from independent to inseparable, reflecting the gradual deepening of the alignment.

\subsection{Enterprise Technological Capability}

To gain an advantage in the market competition, enterprises try to increase the sale of products and occupy the largest possible market, the key to which relies on the product technology, price advantage, product service, etc. The high level of technology in products must be achieved by improving the company's technological innovation capability, and at a deeper level, by improving the enterprise technological capability.

Enterprise technological capability refers to the ability of enterprises to obtain advanced technology and information from the external, and combine it with internal knowledge to create new technology and information, realize technological innovation and widespread application, and at the same time make technology and knowledge available for reserve and accumulation[3].

The improvement of the enterprise technological capability is a gradual accumulation process, which is realized through years of research and development, technology introduction and absorption. As different researchers have different analytical perspectives on the structure of technological capability, the references to the technological capability structure are also different with a few agreements. In our research, we think that the structure of technological capability can be examined in terms of the process of improving the enterprise technological capability, which consists of two aspects, technology absorption capability and technology development capability. In order to acquire the potential knowledge to enhance the enterprise technological capability, enterprises must take the initiative to carry out systematic technology absorption and continuously improve business professional skills in various functions through technology development and application, so as to realize the innovation and upgrading of the enterprise technological capability.

\subsubsection{Enterprise technology absorption capability}

The absorption and integration of external knowledge into the business is critical for the improvement of the enterprise technological capability[4]. Enterprise technology absorption refers to the process of understanding and interpreting externally acquired technological knowledge and transforming it into internal knowledge through the digestion and absorption of the enterprise, as well as the process of the transformation of enterprise technological knowledge from explicit to implicit[5]. The technological knowledge acquired by the enterprise does not generate value on its own, and therefore, the enterprise can only produce many new product concepts and project by converting the new knowledge introduced from outside into the necessary format according to its own organizational characteristics and integrating it with its own internal knowledge[6].

The deep and broad alignment of cloud computing with the enterprise is conducive to enhancing the enterprise's access to technology from external parties, including suppliers, partners and competitors, and through analysis and interpretation to transforming the acquired technological knowledge into the same structure and format as the existing knowledge within the enterprise, so that it can be accepted and used by the employees to generate new knowledge and ideas. Therefore, we proposed the following hypotheses.

H1: Cloud computing alignment breadth (AB) positively affects the enterprise technology absorption capability (TAC).

$\mathrm{H} 2$ : Cloud computing alignment depth (AD) positively affects the enterprise technology absorption capability (TAC).

\subsubsection{Enterprise technology development capability}

Enterprise technology development is the process by which enterprises integrate external new and existing technologies through technology exchange activities to generate new technologies, and therefore is the application of technical knowledge[5]. Its main manifestation is the renewal or growth of the enterprise technological capability by adjusting the existing framework or creating new knowledge in a new framework based on the existing technological stock to reassemble technology. In accordance with the existing technological conditions and market characteristics, enterprises integrate and use the technological knowledge acquired during the technology acquisition and absorption stage, as well as its original technological knowledge, to produce new solutions to problems, improve existing products and develop new technologies and new products.

The enterprise technology absorption capability provides the momentum and support for enterprise technology development, and good technology absorption capability promotes the absorption and digestion of knowledge by enterprises to better achieve technology development. Therefore, we proposed the following hypothesis.

H3: Enterprise technology absorption capability (TAC) positively affects the enterprise technology development capability (TDC).

\subsection{Environmental Turbulence}

Environmental turbulence refers to the temporary environmental disruption of the organization that is difficult to predict and has a disruptive and often harmful effect on the organization[7]. Environmental turbulence can create crises for firms and reduce their performance[8]. In the field of information system, the most influential classification regarding environmental turbulence is Pavlou and Sawy's method that portrays environmental turbulence in two dimensions, market turbulence and technological turbulence[9]. Market turbulence is the volatility caused by changes in market demand, mainly due to the inability to accurately understand and predict 
the customer profile and needs, or to accurately predict the emergence and changes of competitors. Technological turbulence refers to the volatility due to technological risk, mainly as a result of the inability to accurately understand and predict the development rate or the future of a new technology.

In a market with a turbulent environment, changes in supply and demand are more rapid and frequent[10]. Enterprises have more incentive and demand to quickly integrate the technological knowledge acquired during the technology absorption phase and use it, thereby generating new solutions to problems, improving existing products and developing new technologies and new products to cope with frequent technological and market volatility. In a highly volatile market environment, the contribution of the enterprise technology absorption capability to its technology development capability will be more pronounced. Thus, we have the following.

H4: Environmental turbulence (ET) positively moderates the impact of the enterprise technology absorption capability (TAC) on the enterprise technology development capability (TDC).

\subsection{Control Variables}

In addition to the above-mentioned factors that may have an impact on the technology development capability, we also considered five variables, namely, industry type, enterprise nature, total assets, annual sales and cloud computing budget, which would be placed together in the research model as control variables.

\subsection{Research Model}

Based on the above analysis, the research model proposed in this chapter for the impact of the alignment of cloud computing on the enterprise technological capability is shown in Fig. 1.

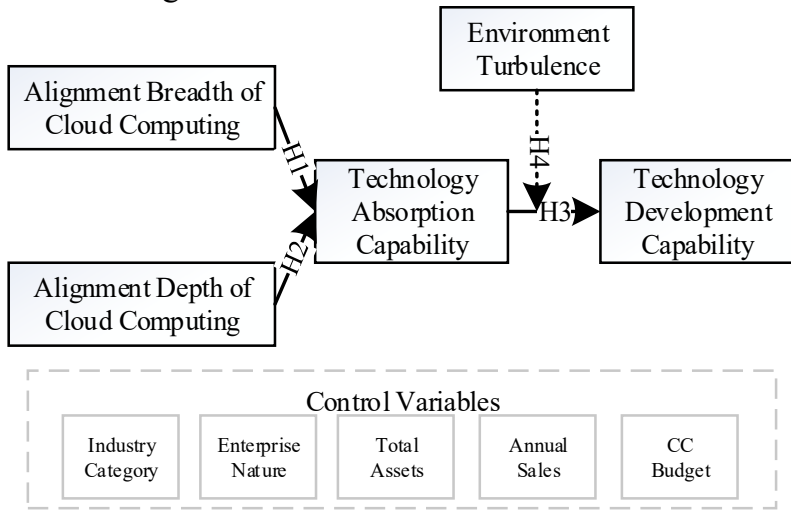

Fig1. Research model of the impact of cloud computing alignment on the enterprise technological capability

\section{Data Collection}

\subsection{Measurement Methods and Questionnaire Design}

This study used questionnaires to collect data. All questions were measured on a Likert scale of 1-5, where 1 indicates complete disagreement and 5 indicates complete agreement.

The two concepts of cloud computing alignment, alignment breadth and alignment depth, have not been measured by scales in the previous literature, so the scale was designed independently in this study. When designing the scale, we followed a complete set of scale development methods (called Q-Sorting) proposed by Moore and Benbasat, which consists of three steps: item creation, scale development, and instrument testing[11].

\subsection{Questionnaire Surveys}

The design of the questionnaire used in this chapter went through the process of designing, pre-testing, and then large-scale collection. During the large-scale collection phase, we were greatly assisted by the Zhongguancun Technology Park Management Committee, which helped us to distribute questionnaires to the enterprises in the park. The survey required that all tested enterprises must be using cloud computing, and only one questionnaire could be completed by each enterprise. The digital questionnaire was distributed through Wenjuanxing, and was collected over 7 days from 16 May to 22 May 2020. 266 questionnaires were collected, and excluding invalid questionnaires, 207 valid questionnaires were finally obtained for data analysis.

\section{Data analysis and results}

\subsection{Sample Characteristics}

The statistical description of the participating companies is shown in Table 1.

Table1. Sample characteristics

\begin{tabular}{|c|c|c|c|}
\hline \multirow[b]{2}{*}{ Items } & \multirow[b]{2}{*}{ Types } & \multicolumn{2}{|c|}{ Sample } \\
\hline & & Frequency & $\begin{array}{c}\text { Percentage } \\
\text { (\%) }\end{array}$ \\
\hline \multirow{3}{*}{$\begin{array}{l}\text { Industry } \\
\text { category }\end{array}$} & Primary industry & 2 & $1 \%$ \\
\hline & Secondary industry & 26 & $13 \%$ \\
\hline & Tertiary industry & 179 & $86 \%$ \\
\hline \multirow{4}{*}{$\begin{array}{c}\text { Enterprise } \\
\text { nature }\end{array}$} & $\begin{array}{l}\text { State-owned and } \\
\text { State-holding } \\
\text { enterprises }\end{array}$ & 18 & $8.5 \%$ \\
\hline & $\begin{array}{l}\text { Collective } \\
\text { enterprises }\end{array}$ & 1 & $0.5 \%$ \\
\hline & Private enterprise & 180 & $87 \%$ \\
\hline & $\begin{array}{l}\text { Foreign-owned or } \\
\text { joint venture }\end{array}$ & 8 & $4 \%$ \\
\hline \multirow{3}{*}{$\begin{array}{l}\text { Total assets } \\
\text { (Yuan) }\end{array}$} & $\begin{array}{l}\text { Less than } 40 \\
\text { million }\end{array}$ & 143 & $69 \%$ \\
\hline & $\begin{array}{l}40 \text { million- } 400 \\
\text { million }\end{array}$ & 42 & $20 \%$ \\
\hline & $\begin{array}{l}\text { More than } 400 \\
\text { million }\end{array}$ & 22 & $11 \%$ \\
\hline \multirow{3}{*}{$\begin{array}{l}\text { Annual } \\
\text { Sales }\end{array}$} & $\begin{array}{l}\text { Less than } 30 \\
\text { million }\end{array}$ & 144 & $70 \%$ \\
\hline & $\begin{array}{l}30 \text { million-300 } \\
\text { million }\end{array}$ & 39 & $19 \%$ \\
\hline & $\begin{array}{l}\text { More than } 300 \\
\text { million }\end{array}$ & 24 & $11 \%$ \\
\hline \multirow{2}{*}{$\begin{array}{c}\text { Cloud } \\
\text { computing }\end{array}$} & Less than 100000 & 131 & $63 \%$ \\
\hline & $100000-1$ million & 53 & $26 \%$ \\
\hline
\end{tabular}




\begin{tabular}{|c|l|l|l|}
\hline $\begin{array}{l}\text { budget } \\
\text { (Yuan) }\end{array}$ & $\begin{array}{l}1 \text { million-10 } \\
\text { million }\end{array}$ & 15 & $7 \%$ \\
\cline { 2 - 4 } & $\begin{array}{l}\text { More than } 10 \\
\text { million }\end{array}$ & 8 & $4 \%$ \\
\hline
\end{tabular}

\subsection{Test of Reliability and Validity}

In this paper, Cronbach's Alpha coefficient and the Composite Reliability coefficient were used to measure questionnaire reliability. From the results in Table 2, the Cronbach's Alpha coefficient and the Composite Reliability coefficient were greater than 0.8 for all variables, which indicates that the questionnaire has a good level of reliability.

Table2. Reliability and AVE

\begin{tabular}{|c|l|l|l|l|l|}
\hline & \multicolumn{1}{|c|}{ AB } & \multicolumn{1}{|c|}{ AD } & \multicolumn{1}{c|}{ TAC } & \multicolumn{1}{|c|}{ TDC } & \multicolumn{1}{c|}{ ET } \\
\hline Cronbach's alpha & 0.965 & 0.947 & 0.949 & 0.954 & 0.891 \\
\hline Composite reliab. & 0.946 & 0.925 & 0.920 & 0.928 & 0.816 \\
\hline Avg. var. extrac. & 0.902 & 0.817 & 0.862 & 0.875 & 0.733 \\
\hline
\end{tabular}

The questionnaire designed in this study tried to use measures that were all proven to be valid. Besides, the results of the exploratory factor analysis are shown in Table 3. We can see that all the questions corresponded well to relevant concepts.

Table3. Exploratory factor analysis

\begin{tabular}{|c|c|c|c|c|c|}
\hline & AB & AD & TAC & TDC & ET \\
\hline AB1 & $(0.612)$ & & & & \\
\hline AB2 & $(0.614)$ & & & & \\
\hline AB3 & $(0.617)$ & & & & \\
\hline AD1 & & $(0.574)$ & & & \\
\hline AD2 & & $(0.606)$ & & & \\
\hline AD3 & & $(0.618)$ & & & \\
\hline AD4 & & $(0.592)$ & & & \\
\hline TAC1 & & & $(0.623)$ & & \\
\hline TAC2 & & & $(0.613)$ & & \\
\hline TAC3 & & & $(0.588)$ & & \\
\hline TDC1 & & & & $(0.632)$ & \\
\hline TDC2 & & & & $(0.629)$ & \\
\hline TDC3 & & & & $(0.621)$ & \\
\hline ET1 & & & & & $(0.706)$ \\
\hline ET2 & & & & & $(0.765)$ \\
\hline ET3 & & & & & $(0.698)$ \\
\hline
\end{tabular}

In addition, the table of correlation coefficients of concepts is shown in Table 4.

Table4. Correlation coefficients of variables (square root of AVE on the diagonal)

\begin{tabular}{|c|c|c|c|c|c|}
\hline & AB & AD & TAC & TDC & ET \\
\hline AB & $(0.950)$ & & & & \\
\hline AD & 0.824 & $(0.904)$ & & & \\
\hline TAC & 0.619 & 0.623 & $(0.928)$ & & \\
\hline TDC & 0.528 & 0.583 & 0.847 & $(0.935)$ & \\
\hline ET & 0.485 & 0.529 & 0.375 & 0.328 & $(0.856)$ \\
\hline
\end{tabular}

It can be seen that all AVEs are greater than 0.7 and the square root of AVE is greater than the correlation coefficients of all other concepts. Therefore, we can consider that the questionnaire has good aggregation and differentiation validity.

\subsection{Analysis of the Structure Equation Model}

We performed a model test using a structural equation model and the results are shown in Fig. 2.

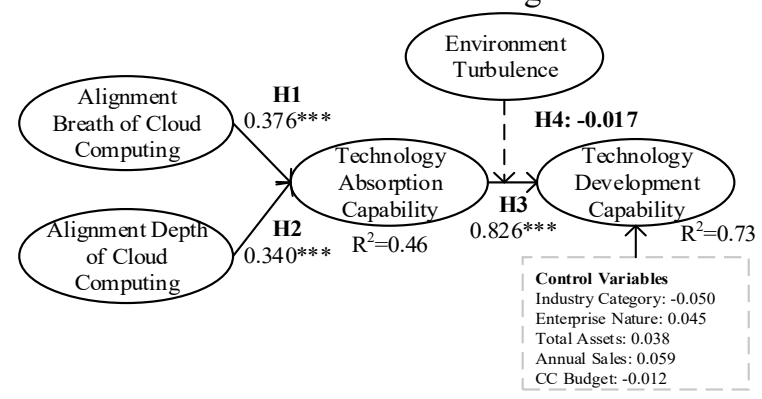

Note: The solid line path is significant. Significant control variables are highlighted in bold. $* \mathrm{p}<0.05 ; * * \mathrm{p}<0.01$; $* * * \mathrm{p}<0.001$.

Fig2. Research model results for the impact of cloud computing alignment on the enterprise technological capability

\section{Discussion}

As a result of the above empirical studies, this paper has the following key findings.

\subsection{The impact of the breadth of cloud computing alignment on the enterprise technology absorption capability}

Alignment breadth has a significant positive impact on enterprise technology absorption capability $(\beta=0.376$, $\mathrm{P}<0.001$ ), that means the alignment of cloud computing and enterprise in breadth enhances enterprise technology absorption capability, hence H1 was supported. This suggests that the more widely enterprises have achieved the alignment of business and cloud computing, the stronger the technology absorption capability is. When the cloud computing alignment is realized from a single department to multiple departments and to all departments, cloud computing and the organization achieve mutual matching and mutual alignment, all departments achieve information alignment and even from the supply chain perspective, the enterprise integrate with upstream suppliers and downstream distributors, so that the enterprise is more likely to have strong technology absorption capability, which enables it to acquire and absorb technological knowledge from the external community, including suppliers, partners, and competitors, etc.

\subsection{The impact of the depth of cloud computing alignment on the enterprise technology absorption capability}

As the empirical results show, the depth of cloud computing alignment has a significant positive impact on 
the enterprise technology absorption capability $(\beta=0.340$, $\mathrm{P}<0.001$ ), that means the alignment of cloud computing and enterprise in depth will enhance the technology absorption of enterprises, hence $\mathrm{H} 2$ was supported. This suggests that enterprises that have achieved business-tocloud alignment at a deeper level are more capable of technology absorption. From mechanical to organic and to innovative alignment, the deeper the alignment becomes as enterprises achieve information integration and knowledge sharing across all business dimensions, the more likely it is that enterprises will be able to use cloud computing to generate strong technology absorption capability to acquire and absorb technological knowledge from external parties, including suppliers, partners and competitors.

\subsection{The impact of the enterprise technology absorption capability on the technology development capability}

As shown by the empirical results, the enterprise technology absorption capability has a significant positive impact on the enterprise technology development capability $(\beta=826, \mathrm{P}<0.001)$, that means the enterprise technology absorption capability enhances the enterprise technology development capability, hence H3 was supported too. This shows that technology absorption by enterprises provides impetus and support for their technology development, and that good technology absorption capability can promote the absorption and digestion of knowledge by enterprises and better technology development, thus promoting enterprises to generate new solutions to problems, improve existing products and develop new technologies and new products.

\subsection{The impact of the interaction of the enterprise technology absorption capability and environmental turbulence on the enterprise technology development capability}

The interaction of the enterprise technology absorption capability and environmental turbulence does not have a significant positive effect on the enterprise technology development capability $(\beta=-0.017, \mathrm{P}>0.05)$, that means environmental turbulence does not positively moderate the effect of the enterprise technology absorption capability on the enterprise technology development capability, thus H4 wasn't supported. This is a completely opposite conclusion to what was expected, and therefore an interesting finding. This suggests that in a more turbulent environment, businesses with lower technology absorption are more capable of technology development; in a less dynamic environment, businesses with higher technology absorption are more capable of technology development. One possible explanation is that, in a more turbulent environment, technology absorption is not a major factor influencing the enterprise technology development capability. Other factors, such as the company's internal technology alignment capability, internal product and process innovation capability, and relationship management with customers and partners, become major factors in the enterprise technology development. But in a less turbulent environment, technology absorption is a major factor influencing the company's technology development.

\subsection{The impact of control variables on the enterprise technology development capability}

We used five control variables to illustrate alternative explanations for the enterprise technology development capability. None of the control variables had a significant impact on the enterprise technology development capability.

\section{Conclusions}

Technological capability is one of the most core competences of enterprises, and this paper examined the impact of the alignment of cloud computing on the enterprise technological capability. We selected the enterprises in Zhongguancun Technology Park as the sample source. To begin with, we classified the alignment of cloud computing into alignment breadth and depth. Then, a theoretical model was proposed to study how alignment breadth and depth influences the enterprise technology development capability by affecting the enterprise technology absorption capability, and the moderation role of environmental turbulence was considered. Finally, we examined the proposed research model and research hypotheses through empirical studies, proving that both the deep and wide alignment of cloud computing can enhance the enterprise technology absorption capability and thus enhance enterprise technology development capability, which provided a basis for the theoretical and industry to understand how cloud computing alignment can enhance enterprise technological capability.

Due to the impact of the COVID-19 epidemic, this study encountered great difficulties in both preliminary research and data collection, resulting in some study limitations and deficiencies, such as insufficient sample size. In the follow-up study, this study will expand the sample source, not only limited to the enterprises in Zhongguancun Technology Park, but also study the impact of cloud computing innovation technology on the value creation and capability promotion of enterprises in a wider range.

\section{Acknowledgment}

This research is supported by Beijing Social Science Foundation Project 15JGC180.

\section{References}

1. Armbrust M, Fox A, Griffith R, Joseph A D, Katz R, Konwinski A, Lee G, Patterson D, Rabkin A, Stoica I. A view of cloud computing [J]. Communications of the ACM, 2010, 53(4): 50-58.

2. QI X Y, An empirical study of information technology 
integration and its impact on organizational performance [D]. Changchun: Jilin University, 2011.

3. WEI J., XU Q R. Study on the relation between the enterprise's technological capability and the technological innovation capabiltiy[J]. Science Research Management, 1996,17(1):22-16.

4. Cohen, W. M., Levinthal, D. A. Absorptive Capacity: A New Perspective on Learning and Innovation[J]. Administrative Science Quarterly, 1990,35(1):128152.

5. TANG C A. Research on the growth and evolution of technological capability of high-tech cluster enterprises based on Network [D]. Hunan: Central South University, 2009.

6. YANG T, LI S C. The Impact of Strategic Purchasing on Technological Capability: An Analysis of Network Relationship Perspective[J]. Business Review, 2012, 24(10):150-156.

7. Meyer A D. Adapting to environmental jolts [J]. Administrative Science Quarterly, 1982, 27(4): 515537.

8. Sine W D, David R J. Environmental jolts, institutional change, and the creation of entrepreneurial opportunity in the US electric power industry [J]. Research Policy, 2003, 32(2): 185-207.

9. Pavlou P A, El Sawy O A. From IT leveraging competence to competitive advantage in turbulent environments: The case of new product development [J]. Information Systems Research, 2006, 17(3): 198227.

10. Lee H L. The triple-A supply chain [J]. Harvard Business Review, 2004, 82(10): 102-113.

11. Moore G. C., and Benbasat I. 1991. Development of an instrument to measure the perceptions of adopting an information technology innovation. Information Systems Research. 2(3): 192-222. 